\title{
Exposure to volatile organic compounds while commuting in Taichung, Taiwan
}

\author{
Hsien-Wen $\mathrm{Kuo}^{\mathrm{a}, *}$, Hsien-Chi Wei ${ }^{\mathrm{a}}$, Chiu-Shong Liu ${ }^{\mathrm{b}}$, Yin-Yin $\mathrm{Lo}^{\mathrm{a}}$, \\ Wen-Chin Wang ${ }^{\mathrm{c}}$, Jim-Shoung Lai ${ }^{\mathrm{c}}$, Chang Chuan Chan ${ }^{\mathrm{d}}$ \\ anstitute of Environmental Health, China Medical College, No. 91, Hsueh-shih Road, Taichung, Taiwan \\ ${ }^{\mathrm{b}}$ Department of Family Medicine, China Medical College Hospital, Taichung, Taiwan \\ ${ }^{\mathrm{c} S}$ chool of Occupational Safety and Health, China Medical College, Taichung, Taiwan \\ ${ }^{\mathrm{d}}$ Institute of Occupational Medicine and Industrial Hygiene, College of Public Health, National Taiwan University, Taipei, Taiwan
}

Received 18 February 1999; accepted 23 August 1999

\begin{abstract}
The objective of this study was to compare volatile organic compounds (VOC) concentrations from six main roads in Taiwan's third largest city (Taichung) and determine factors that affect VOC concentrations. Twenty-two VOC compounds were determined on six roads using US E.P.A method TO-17. $0.2 \mathrm{~g}$ of Carbopack B was used as an adsorbant collector and thermal desorption and gas chromatography/mass spectrometry (GC/MS) techniques were used to analyze VOCs. Results showed that car and motorcycle commuters were exposed to the highest VOC concentrations on Ta-Ya Road (2149 and $1343 \mu \mathrm{g} \mathrm{m}^{-3}$, respectively). Except for Ta-Ya Road and Chung-Kang Road, motorcycle commuters were exposed to higher VOC concentrations than their driving counterparts. Four sampling periods were used in the study; exposure to VOC concentrations was highest from 7:30 to 8:30 AM for motorcycle commuters $\left(1515 \mu \mathrm{g} \mathrm{m}^{-3}\right)$ and from 5:00 to 6:00 AM for car commuters $\left(1071 \mu \mathrm{g} \mathrm{m}^{-3}\right)$, while concentrations for all commuters were lowest from 2:00 to 3:00 P.M. Concentrations were negatively correlated to percentage of vacant lots along the road (PVL), yet not correlated to traffic volume. The ratios for toluene, benzene, xylene, and ethylbenzene ( $\mathrm{T}: \mathrm{B}: \mathrm{X}: \mathrm{E})$ were similar for car commuters $(5.5: 2.1: 2.6: 1.0)$ and motorcycle commuters $(5.7: 2.0: 2.6: 1.0)$ which, combined with other published data, strongly suggest a vehicular source for hydrocarbons in Taichung. Comparing these concentrations, Taichung was slightly lower than Taipei but 2-30 times higher than cities of other countries. It is concluded that the chronic exposure to high concentrations of hydrocarbons may pose a serious health risk to commuters in Taichung (C) 2000 Elsevier Science Ltd. All rights reserved.
\end{abstract}

Keywords: Benzene; Toluene; Automobile emissions; Hydrocarbons

\section{Introduction}

Taichung, is densely populated and relies on cars and motorcycles as the main modes of transportation. According to a 1996 government report, the number of motor vehicles registered in Taichung totaled 593,047.

\footnotetext{
* Corresponding author. Tel.: + 886-4-2054076; fax: + 8864-2019901.

E-mail address: wukuo@mail.cmc.edu.tw (H.-W. Kuo).
}

Cars and motorcycles accounted for 35 and 59\%, while trucks and buses accounted for only 4.3 and $1.7 \%$. The report also revealed that Taichung's nonmethane hydrocarbon annual emissions totaled 31,031 metric tons, half of which was produced by mobile sources. Among stationary sources, the commercial industry and industrial parks accounted for the highest percentages, 20 and $15 \%$. Vehicle emission is the biggest source of air pollution in metropolitan areas in Taiwan. There are approximately $15,000,000$ motor vehicles registered in Taiwan. The average density is 420 vehicles $\mathrm{km}^{-2}$. In 1994, 69\% of the 
total $7.68 \times 10^{9} 1$ of gasoline sold was unleaded. Aromatic contents in unleaded and leaded gasoline were estimated between $30-40$ and $25-30 \%$, respectively. Annual emission of non-methane hydrocarbons was estimated at $1,000,000$ tons, of which motorcycles and cars produced 24 and $18 \%$.

Taichung is situated in a basin that allows air pollutants to concentrate rather than be removed by winds, similar to other cities in Taiwan, such as Taipei. According to Chan et al. (1994), Taipei motorcycle commuters were exposed to $384 \mu \mathrm{g} \mathrm{m}^{-3}$ of benzene compared to $166.5 \mu \mathrm{g} \mathrm{m}^{-3}$ for public bus commuters. These results were 2-30 times higher than those found in Western cities. Chan estimated that the cancer risk for the typical Taipei commuter was $7.5 \times 10^{-6}-1.8 \times 10^{-5}$. In their comparison of ambient air levels of VOCs in Latin American and Asian cities, Gee and Sollars (1998) reported that volatile organic compounds (VOCs) concentrations in the Latin American cities were similar yet considerably lower than those found in the Asian cities. The relatively low-VOC concentrations found in Quito (Ecuador) might be due to its high altitude (approx. $3000 \mathrm{~m}$ above sea level) which allows for the use of fuels with low aromatic compounds. In comparison with these cities, VOC exhaust emissions in Taichung are significantly higher. This is primarily due to Taiwan's widespread use of unleaded fuels that started in 1991. Unleaded fuels contain more aromatic constituents than leaded fuels and also elevate emission concentrations from vehicles not equipped with a catalytic converter. High-VOC concentrations in dense urban areas such as Taichung, with certain geographical factors (located in a basin, narrow roads, PVL, location of city in relation to mountains and the coast), could pose a serious threat to health and environment. This study was undertaken to determine VOC concentrations and their related factors and to provide a set of data that can be used for comparison with other cities, e.g. Taipei.

\section{Methods}

\subsection{Sampling locations}

Taichung was selected as a representative urban area because of its remarkable density and its status as Taiwan's third largest city. The six main roads investigated were chosen based on the criteria that each is a major thoroughfare that connects Taichung's suburban areas with downtown and typically has heavy rush hour traffic. They are: Chung-Kang Road (CK), Ta-Ya Road (TY), Wen-Hsin Road (WH), Bei-Tun Road (BT), KuoKuang Road (KK), and Fu-Hsing Road (FH). The site map is shown in Fig. 1. Characteristics of these roads (width, number of intersections, percentage of vacant lots along the road, number of gas stations, traffic density) varied considerably.

\subsection{Sampling and analytical methods}

The 22 chemicals chosen for analysis were separated into two different standard solutions. Mix 1A contained 9 different chemicals (heptane, ethylbenzene, isopropylbenzene, $o$-xylene, $m$-xylene, $p$-xylene, benzene, toluene,

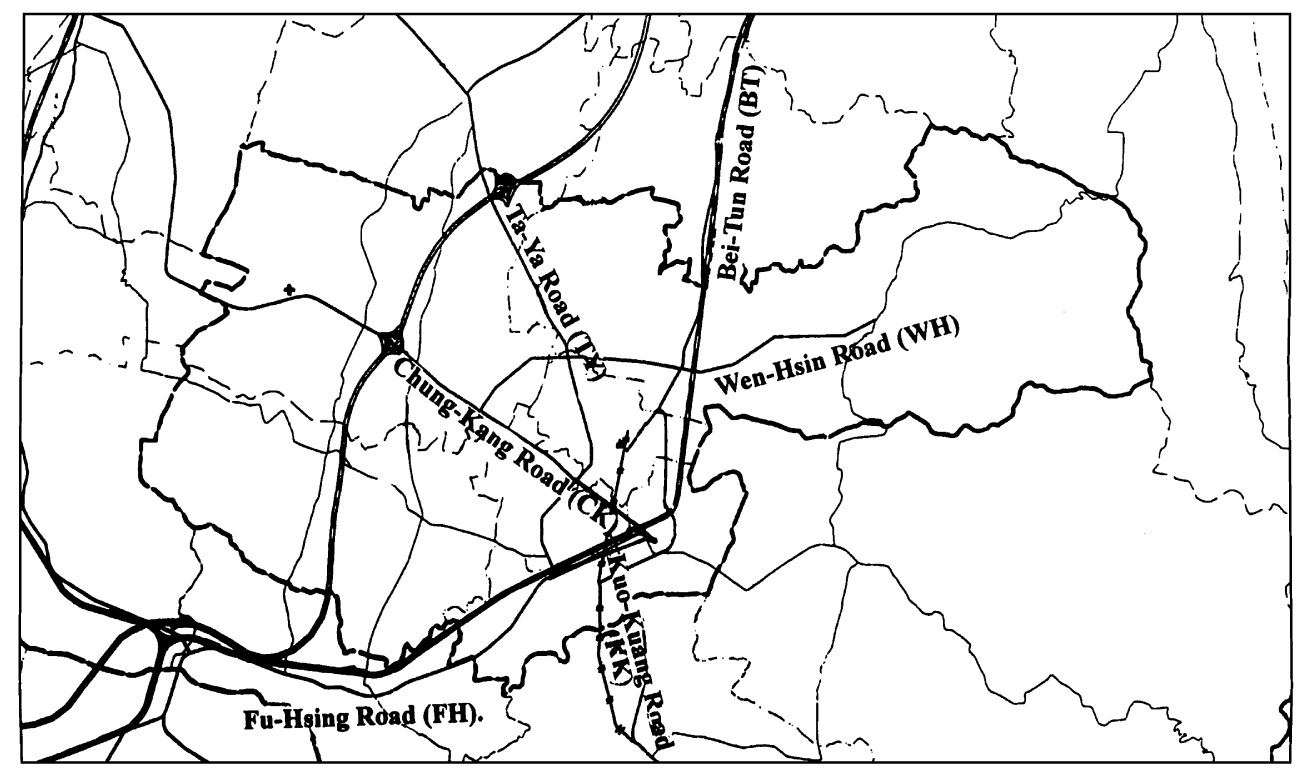

Fig. 1. The six sampling sites in Taichung map. 
1-heptane) and Mix 1B contained 13 different chemicals (acrylonitrile, chlorobenzene, 1,2-dichloroethane, 1,1,1-trichloroethane, 1,2-dichloropropane, 1,2-dibromomethane, bromoform, tetrachloroethylene, 1,3-dichloropropane, allyl chloride, bromobenzene, carbon tetrachloride, chloroform, and trichloroethylene). Sampling and analysis methods were modified versions of US E.P.A. TO-17. The sampling system consisted of stainless-steel tube (length $=9 \mathrm{~cm}$, ID $=0.5 \mathrm{~cm}$ ) with $0.2 \mathrm{~g}$ of Carbopack $\mathrm{B}$ and a low-flow sampling pump (SKC Inc. Model

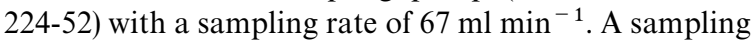
device attached to the collar of the motorist and/or driver performed all commuters (motorcyclists and car drivers) simulation. Samples of automobile driver were taken using measured interior VOC concentrations in the car cabins with windows closed and air conditioning on. For both types of commuters, an average speed of 30-40 k $\mathrm{h}^{-1}$ was maintained whenever possible. Samples were taken from each of the six roads at four periods throughout the day (7:30-8:30 AM, 2:00-3:00 PM, 5:00-6:00 PM, and 9:30-10:30 PM). Two samples were taken during each period, one entering and one exiting the city. Following three days of testing, samples were stored in polyethylene tubes. VOC analysis was performed by high-resolution GC/MS (Perkin-Elmer Q-Mass 910). Sampling tubes were desorbed using an automatic thermal desorption device (Perkin-Elmer ATD 400). The oven temperature was set at $325^{\circ} \mathrm{C}$ for $15 \mathrm{~min}$ and a desorb flow used helium as a carrier gas. The low $\left(5^{\circ} \mathrm{C}\right)$ and high $\left(325^{\circ} \mathrm{C}\right)$ trap temperatures were held for $5 \mathrm{~min}$ at each extreme. For GC/ MS, a capillary column (WCOT Fused Silica $60 \mathrm{~m} \times 0.25 \mathrm{~mm}$ ID $\times 0.25 \mu \mathrm{m})$ was used with an initial oven temperature of $35^{\circ} \mathrm{C}$ (held for $8 \mathrm{~min}$ ) at a rate of $5^{\circ} \mathrm{C} \min ^{-1}-50^{\circ} \mathrm{C} \mathrm{min}^{-1}$ (held for $8 \mathrm{~min}$ ), followed by a rate of $6^{\circ} \mathrm{C} \min ^{-1}-75^{\circ} \mathrm{C}$, and at a rate of $45^{\circ} \mathrm{C} \mathrm{min}^{-1}-200^{\circ} \mathrm{C} \mathrm{min}^{-1}$ (held for $1 \mathrm{~min}$ ). Its retention time and mass spectrum confirmed VOC compound identification. The quantification of target VOCs was achieved by using the calibration curves of six different concentrations of target compounds. The pilot study results showed that Mix 1B chemical concentrations were very low, so they were not included in the field study. This is because there are no petrochemical plants near Taichung. Therefore, this study was concerned only with the VOCs that combined to form Mix 1A (heptane, ethylbenzene, isopropylbenzene, $o$-xylene, $m$-xylene, $p$ xylene, benzene, toluene, 1-heptane).

\subsection{Quality control}

A calibration curve was set up for each of the six different concentrations. Correlation coefficients ranged from 0.9980 to 0.9999 . Three sampling tubes were spiked with $10 \mathrm{ng}$ of each VOC standard to determine the limits of detection (LODs). LODs ranged from 22.51 to
$54.06 \mathrm{ng}$. VOC desorption efficiency at $325^{\circ} \mathrm{C}$ for $15 \mathrm{~min}$ ranged from 97 to $100 \%$. Reproducibility for all VOCs (except for chloroform and 1,2-chloroethane) was less than $10 \%$. Two sampling devices were operated simultaneously on three different occasions to determine consistency (result differences had to be under $25 \%$ ). Average recovery rates based on three amounts of VOCs $(100$, $500,1000 \mathrm{ng}$ ) not including chloroform and 1,2-chloroethane, ranged from 86.5 to $122.31 \%$. Blank tests were performed in the field and laboratory to determine contaminant levels.

\section{Results}

In comparison, CK and TY had the largest widths, four and three lanes, respectively (Table 1). KK and TY had the highest number of intersections $\mathrm{km}^{-1}$ (4.29 and 3.36), and CK and BT had the lowest (0.77 and 1.23). Roads with the highest and lowest percentages of vacant lots (PVL) were CK $(12.5 \%)$ and BT $(1.3 \%)$ and TY $(5.6 \%)$. Roads with the highest and lowest number of gas stations $\mathrm{km}^{-1}$ were $\mathrm{FH}(0.52)$ and CK (0.09). Highest and lowest traffic density (number of vehicles per min) was found on CK (51.2) and FH (12.9). Roads with the highest and lowest average driving speed $\left(\mathrm{km} \mathrm{h}^{-1}\right)$ were $\mathrm{CK}$ (42.6) and TY (19.2).

Commuter exposure to VOC concentrations varied significantly based on the six roads (Table 2). Average exposure concentrations for car commuters were highest on TY $\left(2149 \mu \mathrm{g} \mathrm{m}^{-3}\right)$ and lowest on FH $\left(443 \mu \mathrm{g} \mathrm{m}^{-3}\right)$. The highest maximum VOC $\left(2975 \mu \mathrm{g} \mathrm{m}^{-3}\right.$ on TY) was five times greater than the lowest maximum $\left(620 \mu \mathrm{g} \mathrm{m}^{-3}\right.$ on $\mathrm{FH})$. Average exposure concentrations for motorcycle commuters were highest on TY $\left(1343 \mu \mathrm{g} \mathrm{m}^{-3}\right)$ and lowest for $\mathrm{WH}\left(627 \mu \mathrm{g} \mathrm{m}^{-3}\right)$. The highest maximum VOC $\left(2910 \mu \mathrm{g} \mathrm{m}^{-3}\right.$ on TY) was approximately three times greater than the lowest maximum $\left(1091 \mu \mathrm{g} \mathrm{m}^{-3}\right.$ on WH). Except for TY, all exposure concentrations for motorcyclists were higher than those for drivers. From Table 1, exposure to VOC concentrations (for drivers and motorcyclists) were positively correlated to the number of intersection $\mathrm{km}^{-1}(r=0.3$ and 0.26$)$ and number of gas stations $\mathrm{km}^{-1}(r=0.37$ and 0.66$)$. Exposure to VOC concentrations (for drivers and motorcyclists) were negatively correlated to road width $(r=-0.14$ and $-0.60)$, PVL $(r=-0.22$ and -0.77$)$ and average driving speed $(r=-0.21$ and -0.40$)$. In general, correlations between exposure to VOC concentrations and these factors were lower among automobile drivers because the enclosed cabin more effectively isolated the driver from exhaust from vehicles. In two previous studies (Flachsbart, 1987; Weisel, 1992), VOC concentrations in the automobile's interior were highly dependent upon traffic density and driving speed. Because increased traffic density contributes to source strength and decreases 
Table 1

Comparison of the basic characteristics of six roads in Taichung

\begin{tabular}{|c|c|c|c|c|c|c|c|}
\hline $\mathrm{CK}$ & 4 & $17(0.77)$ & 12.5 & $2(0.09)$ & 51.2 & 22.0 & 0.7 \\
\hline TY & 2 & $21(3.36)$ & 5.6 & $3(0.48)$ & 21.5 & 16.5 & 0.33 \\
\hline WH & 3 & $16(1.45)$ & 10.5 & $3(0.27)$ & 36.4 & 15.9 & 0.44 \\
\hline $\mathrm{FH}$ & 2 & $23(2.0)$ & 6 & $6(0.52)$ & 12.9 & 13.4 & 0.41 \\
\hline Car & $-0.14^{\mathrm{a}}$ & 0.30 & -0.22 & 0.37 & 0.03 & - & 0.21 \\
\hline Motorcycle & -0.60 & 0.26 & -0.77 & 0.66 & - & 0.098 & 0.40 \\
\hline
\end{tabular}

${ }^{\mathrm{a}}$ Coefficient of correlation.

Table 2

Comparison of commuter exposure to VOC concentrations $\left(\mu \mathrm{g} \mathrm{m}^{-3}\right)$ from 6 roads

\begin{tabular}{|c|c|c|c|c|c|c|}
\hline TY & $2149 \pm 225$ & 1117 & 2975 & $1343 \pm 366$ & 1058 & 2910 \\
\hline WH & $551 \pm 98$ & 692 & 1066 & $627 \pm 162$ & 575 & 1091 \\
\hline BT & $724 \pm 76$ & 694 & 976 & $1235 \pm 394$ & 1071 & 2123 \\
\hline
\end{tabular}

inter-vehicle distance, higher concentrations of VOCs emitted by adjacent automobiles can penetrate the automobile's interior. Higher driving speeds contribute to greater roadway air turbulence, thereby increasing the dispersion of pollutants and decreasing roadway concentration. However, the current study is unique because contrary to the aforementioned studies, we found that commuter exposure to VOC concentrations were not related to traffic density $(r=0.01$ and 0.09$)$. Geographic conditions such as PVL and road width should not be overlooked when determining factors significant to commuter exposure concentrations. PVL and road width had significant negative correlations with exposure to VOC concentrations for motorcyclists. However, number of gas stations $\mathrm{km}^{-1}$ was positively correlated to exposure to VOC concentrations for motorcyclists. These findings were similar to those reported by Periago (1997), who showed that volume of gasoline sales rise when the temperature rises and airborne VOC concentrations tend to increase in the vicinity of gas stations.

Based on measurements taken during the four periods, results showed that car commuters were exposed to the highest VOC concentrations $\left(1071 \mathrm{\mu g} \mathrm{m}^{-3}\right)$ in the period from 5:00 - 6:00 PM followed by the 7:30-8:30 AM time slot $\left(982 \mu \mathrm{g} \mathrm{m}^{-3}\right)$ (Table 3). For motorcycle commuters, exposure concentrations were highest from 7:30-8:30 AM $\left(1515 \mu \mathrm{g} \mathrm{m}^{-3}\right)$, followed by the 5:00 PM-6:00 PM time period $\left(999 \mu \mathrm{g} \mathrm{m}^{-3}\right)$. Lowest exposure concentrations were found from 2:00-3:00 PM for both car $\left(772 \mu \mathrm{g} \mathrm{m}^{-3}\right)$ and motorcycle commuters $\left(604 \mu \mathrm{g} \mathrm{m}^{-3}\right)$. Exposure concentrations remained high during the 9:30-10:30 PM period which shows that winds do not significantly remove air pollutants from vehicle emissions well after peak rush hours. Wu (1998) used the same sampling and analytical methods as the current authors to monitor VOC concentrations in Taichung and arrived at consistent results. Wu found that VOC concentrations on a week day were higher during night hours (7:30-7:30 AM) than day hours (7:30 AM-7:30 PM) based on two fixed locations (train station and industrial park). However, when measured on the weekend, the results were opposite. This is due to two main factors: Taichung is located in a basin, which makes the removal of air pollutants difficult, and people in Taichung have an active nightlife. The problem of air pollution is exacerbated by several factors which include: the annual average temperature for Taichung is $23^{\circ} \mathrm{C}$, relative humidity is $76 \%$, wind velocity is $1.5 \mathrm{~m} \mathrm{~s}^{-1}$, and there is a potential in Taichung for air pollutants to build up due to stagnant conditions. 
Table 3

Comparison of commuter exposure to VOC concentrations $\left(\mu \mathrm{g} \mathrm{m}^{-3}\right)$ based on 4 periods

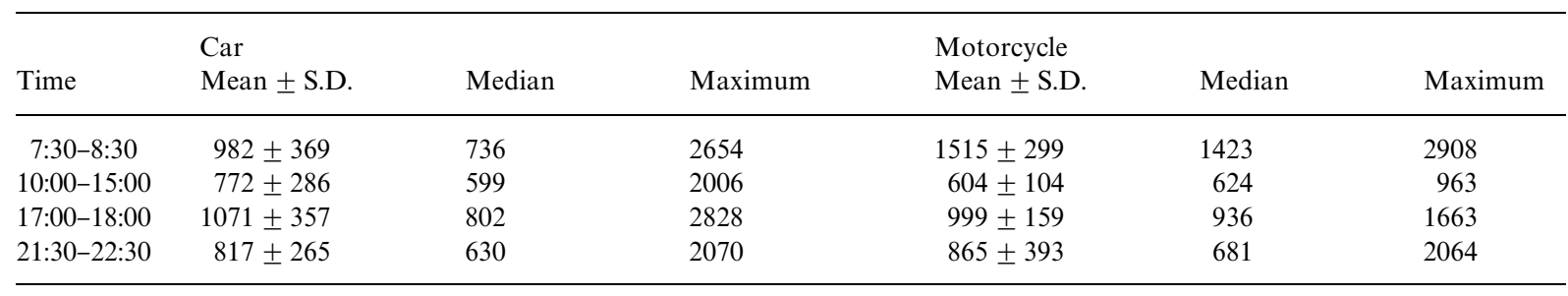

Table 4

Comparison of commuter exposure to VOC concentrations $\left(\mu \mathrm{g} \mathrm{m}^{-3}\right)$ from 12 cities

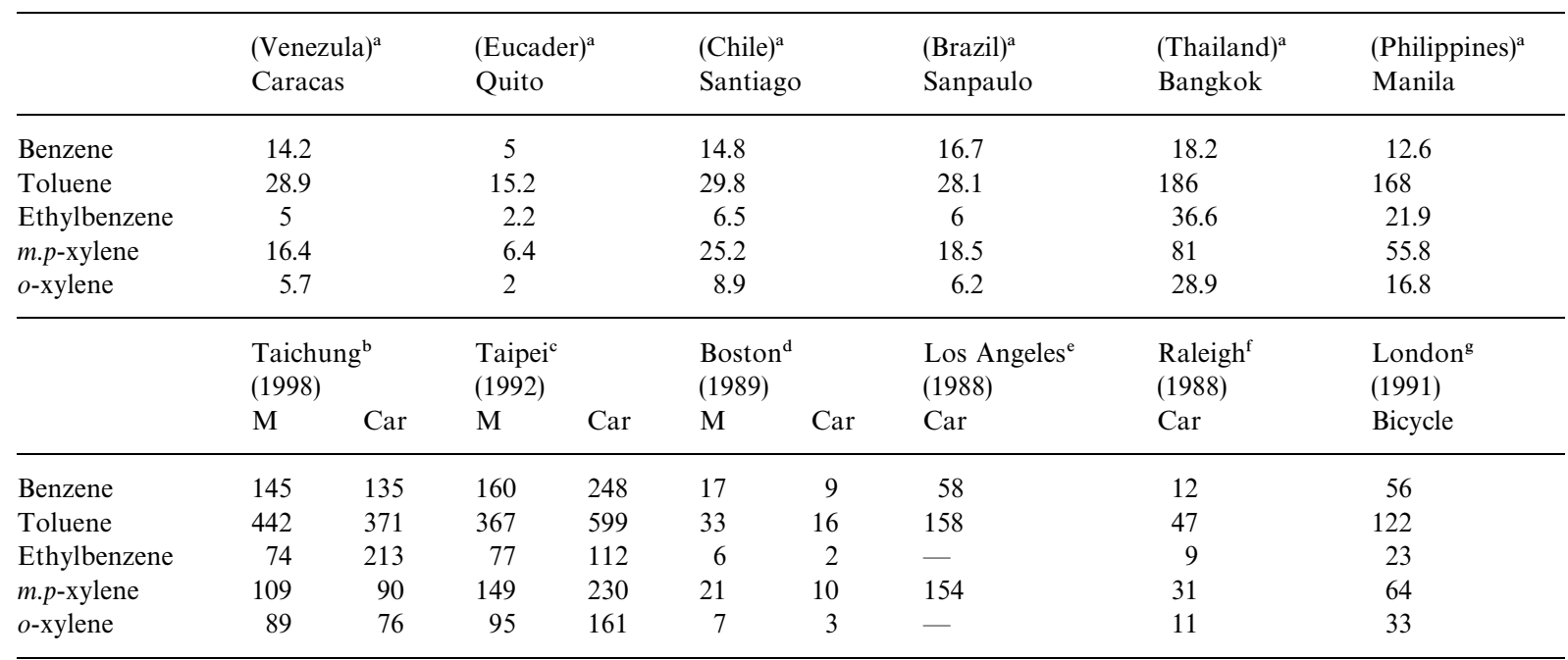

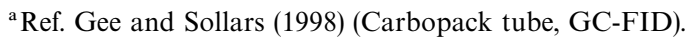

${ }^{\mathrm{b}}$ Current study (modified TO-17 method).

${ }^{\mathrm{c}}$ Ref. Chan et al. (1994) (modified TO-1method).

${ }^{\mathrm{d}}$ Ref. Chan et al. (1992) (charcoal tube, GC-FID).

${ }^{\mathrm{e}}$ Ref. SCAQMD (1989) (TO-14 method).

${ }^{\mathrm{f}}$ Ref. Chan et al. (1991) (TO14 method).

${ }^{\mathrm{g}}$ Ref. Bevan et al. (1991) (Tenax-TA, GC-MS).

Sampling results showed that based on measurements from all individual VOCs, commuters were exposed to the highest concentrations of toluene $\left(371,442 \mu \mathrm{g} \mathrm{m}^{-3}\right)$ and benzene $\left(134,145 \mu \mathrm{g} \mathrm{m}^{-3}\right.$ ) (Table 4). Exposure to isopropylbenzene was lowest $\left(26 \mu \mathrm{g} \mathrm{m}^{-3}\right.$ for both car and motorcycle commuters). Except for 1-heptene, all exposure concentrations were higher for motorcycle than car commuters. The ratios for toluene, benzene, xylene, and ethylbenzene ( $\mathrm{T}: \mathrm{B}: \mathrm{X}: \mathrm{E})$ were similar for car commuters $(5.5: 2.1: 2.6: 1.0)$ and motorcycle commuters $(5.7: 2.0: 2.6: 1.0)$. There was significant inter-correlation between four compounds (T, B, X and E) for cars $(r=0.96-0.99)$ and for motorcycles $(r=0.74-0.97)$. Several VOCs, such as ethylbenzene, xylene and 1,2,4trimethylbenzene, have been used to characterize the emissions from vehicle exhaust (Kelly and Groblicki, 1993; Chan et al., 1995). The ratios of these compounds can be used to determine emission sources. Harkov (1983) found the T:B:X:E ratios for car emissions measured in a tunnel and on a city road were $5: 3: 3: 1$ and $4: 3: 3: 1$, respectively. Levagyi (1991) recommended that the ratio of vehicle emission sources for toluene to benzene was $2: 1$. Because results from the current study are consistent with the aforementioned ratios, Taichung's main source of these VOCs was determined to be vehicle emissions. In his study on airborne volatile aromatics in Tainan, Taiwan (1997), Tsai reported that $(\mathrm{T}: \mathrm{B})$ ratios varied based on different locations with the highest found on a urban rooftop (8.25) and the lowest in a national park (1.29). Based on his 1998 study in Taichung, Wu (1998) found a similar trend in $(\mathrm{T}: \mathrm{B}: \mathrm{X}: \mathrm{E})$ ratios measured at the train station $(10.8: 1.5: 2.5: 1.0)$ and industrial park $(7.4: 1.3: 2.7: 1.0)$. In different studies Wu (1998), Tsai 
et al. (1997) and Chan (1994) reported similar results that showed high toluene to benzene ratios in urban areas. This is due to the use of toluene as a commonly used solvent. The current study found commuter exposure to significantly high concentrations of benzene which is major component in vehicle emissions. In contrast to the Tsai and $\mathrm{Wu}$ studies which found high toluene to benzene ratios because samples were taken from fixed locations, the current study found commuter exposure to toluene from indoor sources was insignificant.

Table 5 compares concentrations of toluene, benzene, xylene, and ethylbenzene among six cities (Taichung, Taipei, Boston, Los Angeles, Raleigh, and London). Concentrations for Taichung (Summer 1998) were slightly lower than those for Taipei (Spring, 1992), but both were significantly higher than those from the other four cities. Based on benzene concentrations, Taichung was 7.9 times higher than Boston (1989), 2.7 times higher than L.A. (1988), 11.2 times higher than Raleigh (1988) and 2.4 times higher than London. Taichung's exceedingly high concentration of benzene might be due to the relatively high concentrations of aromatic components (including benzene) in unleaded gasoline which became widely used in Taiwan in 1991 and the low proportion of emissioncontrolled vehicles in Taiwan. In Finland, the benzene content in gasoline is regulated to be below $5 \%$ and is typically about $3 \%$. Yet, concentrations of other gasoline components are not regulated. In Taiwan, benzene content in gasoline averages $2.8 \%$ but varies slightly based on the location. Chan et al. (1994) reported that vehicles in Taiwan with catalytic converters were minimal among cars and motorcycles because only cars manufactured after 1 July 1990 were required to meet emission standards which were equivalent to those in the United States in 1983.

\section{Conclusion}

Results showed that commuter exposure to VOC concentrations varied widely based on sampling from the six main roads. Primary reasons for this were the percentage of vacant lots along the road (PVL) and road width. Both factors were negatively correlated to commuter exposure concentrations. Contrary to previous studies, VOC concentrations were not significantly correlated to traffic density. The ratios for toluene, benzene, xylene, and ethylbenzene $(\mathrm{T}: \mathrm{B}: \mathrm{X}: \mathrm{E})$ were similar for car commuters $(5.5: 2.1: 2.6: 1.0)$ and motorcycle commuters $(5.7: 2.0: 2.6: 1.0)$. It is apparent that Taichung's primary source of air pollution is vehicle emissions. Concentrations found in Taichung were slightly lower than those found in Taipei but 2-30 times higher than in other countries in Asia, Europe and North and South America. In order to reduce long-term health risks due to VOC exposure, emissions from noncatalyst passenger cars and motorcycles in metropolitan areas have to be greatly reduced first.

\section{Acknowledgements}

We would like to thank the support of NSC (NSC 87-2314-b039-021) for funding this study.

\section{References}

Bevan, M.A.J., Protor, C.J., Baker-Roger, J., Warren, N.D., 1991. Exposure to carbon monoxide, respirable suspended particulates, and volatile organic compounds while commuting by bicycle. Environmental Science and Technology 25, 964-972.

Chan, C.C., Lin, S.H., Her, G.R., 1994. Office worker's exposure to volatile organic compounds while commuting and working in Taipei city. Atmospheric Environment 28, 2351-2359.

Chan, C.C., Ozkaynak, H., Spengler, J.D., Sheldon, L., 1991. Driven exposure to VOC, CO, ozone and $\mathrm{NO}_{2}$ under different driving conditions. Environmental Science and Technology 25, 964-972.

Chan, C.C., Spengler, J.D., Ozkaynak, H., Lefkopoulou, M., 1992. Commuter exposure to VOC in Boston. Massachusettes. Journal Air and Waste Management Association 41, 1594-1600.

Chan, C.C., Nien, C.K., Tsai, C.Y., Her, G.R., 1995. Comparison of tail-pipe emissions from motorcycles and passenger cars. Journal of Air and Waste Management Association 45, 116-124.

Flachsbart, P.G., Merek, G.A., Howes, J.E., Rodes, C.F., 1987. Carbon monoxide exposure of Washington commuters. J. Air Poll. Control Assoc. 37, 135-142.

Gee, I.L., Sollars, C.J., 1998. Ambient air levels of volatile organic compounds in Latin American and Asian cities. Chemosphere 36, 2497-2506.

Harkov, R., 1983. Measurement of selected volatile organic compounds at three location in New Jersey during the summer season. Journal of Air Pollution Control Association 33, 1177-1183.

Kelly, N.A., Groblicki, P.J., 1993. Real-world emissions from a modern production vehicle driven in Los Angeles. Journal of Air and Waste Management Association 43, 1351-1357.

Levagyi, D.A., 1991. Gaseous toxic monitoring in the San Francisco Bay area. A review and assessment of four years of data. The 84th Annual Meeting and Exhibition of the Air and Waste Management Association, Vancouver.

SCAQMD, 1989. "In-vehicle Air Toxics Characterization Study in the South Coast Air Basin: Final Report" South Air Quality Management District (SCAQMD), EI Monte.

Tsai, J.H., Liang, C.P., Lee, D.Z., Sheu, Y.C., Lin, S.J., 1997. Characteristics of airborne volatile aromatics in Tainan. Taiwan. Journal of Environmental Engineering, 406-409.

Weisel, C.P., Lawryk, N.J., Lioy, P.J., 1992. Exposure to emission from gasoline within automobile cabins. Journal Exposure Analytical Environmental Epidemiology 2, 79-96. 